http://jmscr.igmpublication.org/home/ ISSN (e)-2347-176x ISSN (p) 2455-0450

crossref DOI: https://dx.doi.org/10.18535/jmscr/v9i9.04

\title{
Management of Oesophageal Cancer: A 3 Years Retrospective and 1 1/2 years Prospective Analysis
}

\author{
Authors \\ Dr Shrikant Sudam Suryawanshi ${ }^{1}$ Dr Saia Chenkula ${ }^{2}$, Dr John Zohmingthanga ${ }^{3}$, \\ Dr Zothansanga Ralte ${ }^{2}$ \\ ${ }^{1}$ Department of CVTS, L.T.M.G Hospital and Medical College, Mumbai, Maharashtra \\ ${ }^{2}$ Department of General Surgery, Civil Hospital, Aizawl, Mizoram \\ ${ }^{3}$ Department of Pathology, Civil Hospital, Aizawl, Mizoram \\ *Corresponding Author \\ Dr. Shrikant Sudam Suryawanshi \\ (MBBS, DNB General Surgery, MCh CVTS) \\ Assistant Professor, Department of CVTS, L.T.M.G Hospital and Medical College, Sion, Mumbai, India
}

\begin{abstract}
Background: In India, Oesophageal cancer is second most common cancer among males and fourth most common among females and is associated with certain diets and lifestyle

Aim: To study the management protocol and post-operative complications of oesophageal cancer patients at Civil Hospital, Aizawl.

Methods: A Descriptive study (3 years retrospective and 11/2years prospective) was conducted at Civil Hospital, Aizawl, Mizoram from July 2013 to December 2014 (1 1/2 years) amongst 104 patients reporting to Civil Hospital, Aizawl for oesophageal cancer.

Results: Histopathological examination of rescted esophageal specimen showed $95.71 \%$ patients were detected with Squamous cell carcinoma, 4.29\% patients were detected with no proper malignancy/residual tumor. Transhiatal Oesophagectomy (THE) + Gastric pull up (GPU) + Feeding Jejunostomy (FJ) was common (37\%) surgical management procedure was done in patients.

Conclusion: Results of present study suggest that squamous cell carcinoma is the major histologic type found in esophageal cancer patients. Most of patients presented in advance stage and had grave prognosis.

Keywords: Dysphagia, Squamous cell carcinoma, Oesophagus.
\end{abstract}

\section{Introduction}

Oesophageal cancer is eighth most common cancer worldwide and sixth most common cause of death from cancer. ${ }^{1}$ In India, Oesophageal cancer is second most common cancer among males and fourth most common among females and is associated with certain diets and lifestyle ${ }^{2}$
Squamous cell cancer and adenocarcinoma are the most common types of oesophageal carcinomas. ${ }^{3}$ Oesophageal cancer is diagnosed by upper gastrointestinal endoscopy with multiple biopsies. The introduction of endoscopic ultrasound has helped to a very large extent in determining $\mathrm{T}$ and $\mathrm{N}$ stages of disease. However CT scan is needed 
to identify lung and abdominal metastasis. It also helps in assessing the local resectibility of growth by delineating the invasion into mediastinal structures. ${ }^{4}$

Mizoram has the second highest incidence of oesophageal cancer in India, ${ }^{5}$ and Civil Hospital, Aizawl is the main centre for treating these patients, it is high time to have proper documentation of clinical presentation, pathological staging, surgical treatments and survival of of patients with oesophageal cancer.

In Mizoram, the first surgery for oesophageal cancer was done in $2002 .{ }^{6}$ Since then both Trans hiatal oesophagectomy (THE) and Trans thoracic oesophagectomy (TTE) have been performed regularly without proper documentation.

Therefore, a 3 years retrospective and $1 \frac{1 / 2}{2}$ years prospective descriptive study of management of oesophageal cancer conducted in Civil Hospital, Aizawl.

\section{Aim}

To study the management protocol and post operative complications of esophageal cancer patients at Civil Hospital, Aizawl.

\section{Methodology}

A Descriptive study (3 years retrospective and 11/2 years prospective) was conducted at Civil Hospital, Aizawl, Mizoram from July 2013 to December 2014 (1 $1 \frac{1}{2}$ years) amongst the patients reporting to Civil Hospital, Aizawl for oesophageal cancer.

Inclusion criteria: All patients histo-pathologically diagnosed with oesophageal cancer of all ages, sex, \& occupation and who underwent for management of it at Civil Hospital, Aizawl.

Exclusion criteria: Patients who were not willing to participate and bound to loss to follow-up and missing data.

Sample size for study was calculated by considering the report of Population Based Cancer registry, Civil Hosptital, Aizawl, Five Year Report (2007-2011). According to this report the proportion of oesophagal cancer in general population was $8.6 \%$ and sample size calculated by considering this proportion was 104 . Universal sampling method was used for collection of data of $4 \frac{1}{2}$ years (all the histo-pathologically diagnosed cases of oesophageal cancer from July 2010 to December 2014) using pre-validated questionnaire.

Statistical Analysis: Data entered in Microsoft Excel and analysed in SPSS version 16.

\section{Results}

Table no. 1 shows that Socio-demographic distribution of patients. Mean (SD) age of patient was $54.19 \pm 8.89$ years.49.06 \% patients were belonged to age group 50-59 years, followed by $21.15 \%$ in $40-49$ years. This distribution of age is shown in fig. no. 1.

In this study $80.77 \%$ were males and $19.23 \%$ were females. $99.03 \%$ patients were found to be Christians and only $0.97 \%$ patients were found to be Hindu.

History of progressive dysphagia to solids was most common symptom and observed in $91.34 \%$ patients and liquid was noted in $42.31 \%$ patients. Anorexia was seen in $62.5 \%$ patients, followed by chest pain in $52.88 \%$, followed by Vomiting (45.19\%). Odynophagia was noted in $35.58 \%$ of patients. Hoarseness of voice was found in $26.92 \%$ of patients.

For primary evaluation of Oesophagal cancer, routine blood investigations plus Upper GI endoscopy, Chest X-ray, Bronchoscopy, USG abdomen, CECT of abdomen\& thorax, barium swallow were done.

On Upper GI endoscopy, most common site of growth found was middle third of the oesophagus (48.08\%), followed by distal third of oesophagus $(45.19 \%) .54 .81 \%$ of patients were detected with Ulcerative nature of the oesophageal growth and $25 \%$ of patients were detected with ulceroproliferative nature. Squamous cell carcinoma was found in $99.03 \%$ of patients and adenocarcinoma was found in $0.97 \%$ of patients on biopsy of endoscopic specimen. 
Bronchoscopy was done in 54 patients among total 104 patients. In $9.26 \%$ patients were observed with tracheal indentation with narrowing and $3.7 \%$ patients were observed with tracheaesophageal fistula.

Pleural Effusion and Pneumonitis (2.85\%) was common findings over chest $\mathrm{X}$ ray.

Hepatomegaly with ascitis was common finding over USG (4.28\%).

CECT abdomen showed abdominal lymphadenopathy in $28.84 \%$ of the patients. Among patients with abdominal lymphadenopathy on CECT abdomen, (27) 90\% patients had perigastric lymphadenopathy, (2) $6.66 \%$ of the patients had periaortic lymphadenopathy and (1) $3.33 \%$ of the patients had celiac lymphadenopathy.

Total 47 patients who underwent barium swallow, mucosal irregularity was present in $68.09 \%$ of the patients. Dye holding was present in $44.68 \%$ of the patients. Dilation of proximal part was present in $14.9 \%$ of the patients.

Table no. 2 shows the treatment given to patients diagnosed with oesophagal cancer. Transhiatal Oesophagectomy (THE) + Gastric pull up (GPU) + Feeding Jejunostomy (FJ) was done in $37.5 \%$ of the patients, Transthoracic Oesophagectomy (TTE) + GPU+ FJ was done in the $29.81 \%$ of patients. Only feeding jejunostomy (FJ) was done in $22.12 \%$ of the patients and feeding gastrostomy (FG) was done in $1.92 \%$ of the patients. $8.65 \%$ patients could not tolerate surgery so nothing was done in them owing to very poor general condition.

In our study 70 patients underwent oesophageal resection and specimen examined histopathologically, $67(95.71 \%)$ patients were detected with Squamous cell carcinoma, 4.29\% patients were detected with no proper malignancy/residual tumour . No one was detected with adenocarcinoma. This distribution of histopathological diagnosis is shown in fig. no. 2. Out of the 67 patients who were diagnosed with malignancy on histopathological examination among the total patients of oesophagectomy examined histopathologically, $34.33 \%$ patients were detected with well differentiated grade of tumour, $59.70 \%$ patients were detected with moderately differentiated grade of tumour and $5.97 \%$ patients were detected with poorly differentiated grade of tumour.

Of the 70 patients who underwent oesophageal resection, on gross morphological examination of the specimen, $1 / 3$ rd circumference involvement of the oesophagus was observed in $27.14 \%$ of patients, $1 / 2$ circumference involvement was found in $22.86 \%$ of the patients. Full circumference involvement was observed in $25.71 \%$ patients and $3 / 4^{\text {th }}$ circumference involvement was observed $24.29 \%$ of the patients.

Out of the total 95 patients operated for either oesophageal resection or feeding jejunostomy of gastrostomy and assessed for lymph node status, abdominal lymph nodes were affected in $31.58 \%$ of patients and mediastinal lymph nodes were affected in $21.05 \%$ of patients. Both were affected in $11.58 \%$ of patients.

Out of the total 95 patients operated for either oesophageal resection or feeding jejunostomy of gastrostomy and assessed for metastasis, metastasis to distant sites was present in $8.42 \%$ of the patients. Among the patients showing distant spread, metastasis to liver was seen in $7(87.5 \%)$ of the patients and $1(12.5 \%)$ patients showed metastasis to peritoneum.

Out of the 67 patients who were diagnosed with malignancy on histopathological examination among the total patients of oesophagectomy examined histopathologically, based on The American Joint Committee on Cancer (AJCC) staging, instituted in year 1988 on TNM system, $20.90 \%$ patients were detected with stage IIIA, $20.90 \%$ patients were detected with stage IIB. $14.93 \%$ patients were detected with stage IA and IIA each. $11.94 \%$ patients were detected with stage IIIB and $11.94 \%$ patients were detected with stage IB. $4.48 \%$ patients were detected with stage IIIC. This distribution of histopathological diagnosis is shown in fig. no. 3 . 
Table no. 3 shows the post operative complications noted in patients. Death due to post operative sepsis was seen in $2(1.92 \%)$ patients. Death due to cardiac arrest was seen in $7(6.73 \%)$ patients.

Fig. no. 4 showed that out of the 25 patients operated for oesophageal resection in our prospective study period, only $14(56 \%)$ patients came for follow up. Out of the patients came for follow up, 7 (50\%) expired during follow up.
17 patients received neoadjuvant chemotherapy in the prospective study period. Among the patients receiving neoadjuvant chemotherapy, 1 (5.88\%) patient received one cycle of neoadjuvant chemotherapy, $3(17.64 \%)$ patients received two cycles, $8(47.08 \%)$ patients received three cycles, $3(17.64 \%)$ patients received four cycles and 2 $(11.76 \%)$ patients received 6 cycles of neoadjuvant chemotherapy.

Fig. No.1: Distribution of patients according to age group.

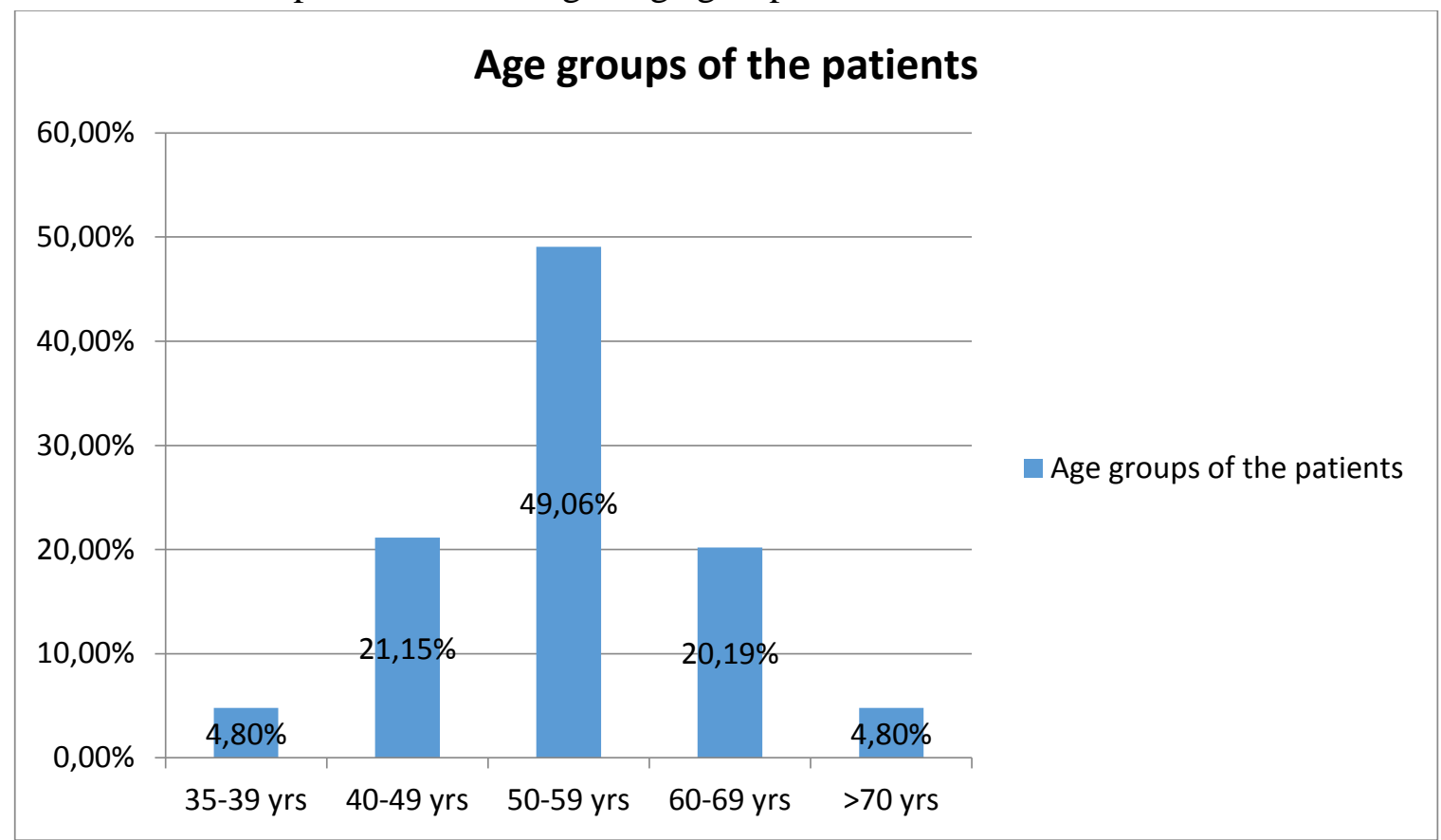

Fig. No. 2: The final histopathological diagnosis of oesophageal resection

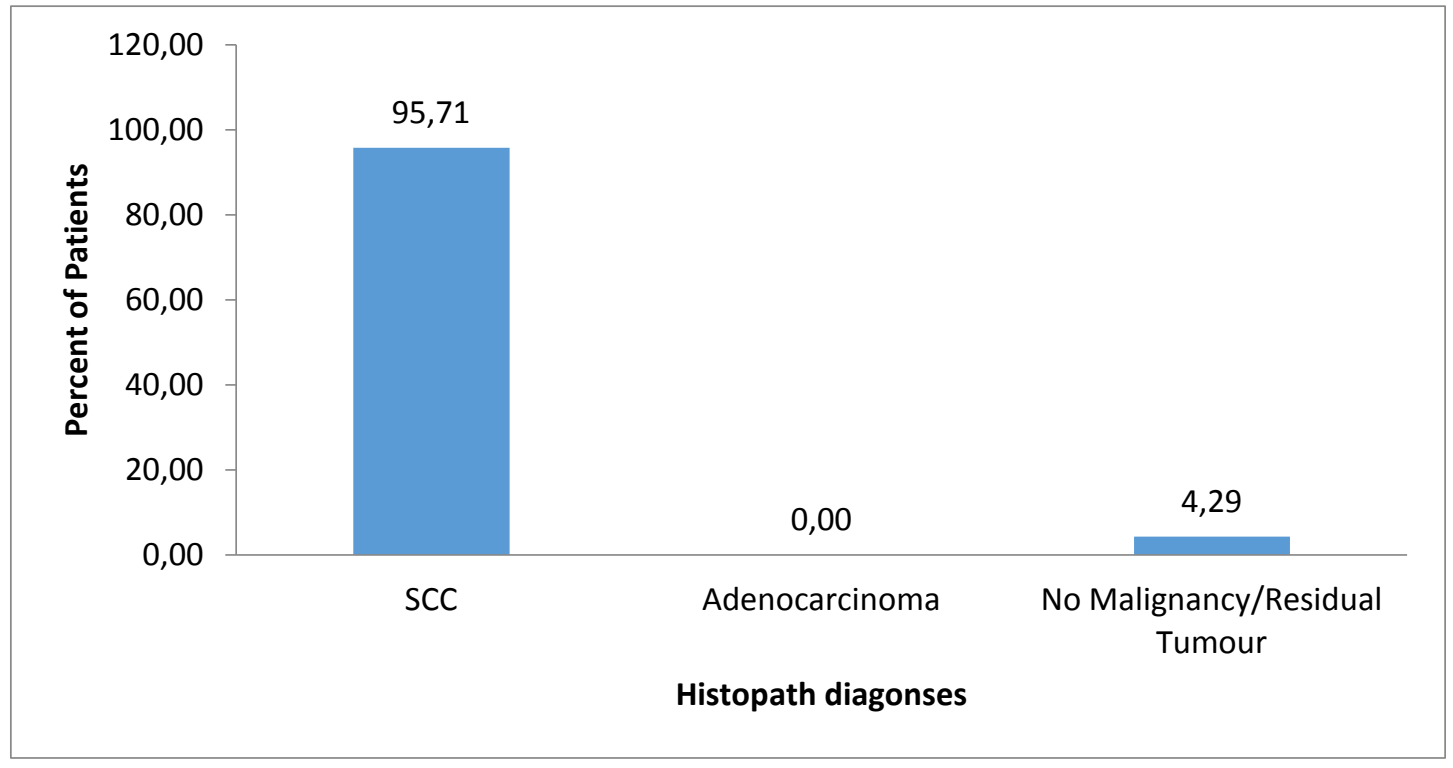


Fig No. 3: The TNM staging of patients

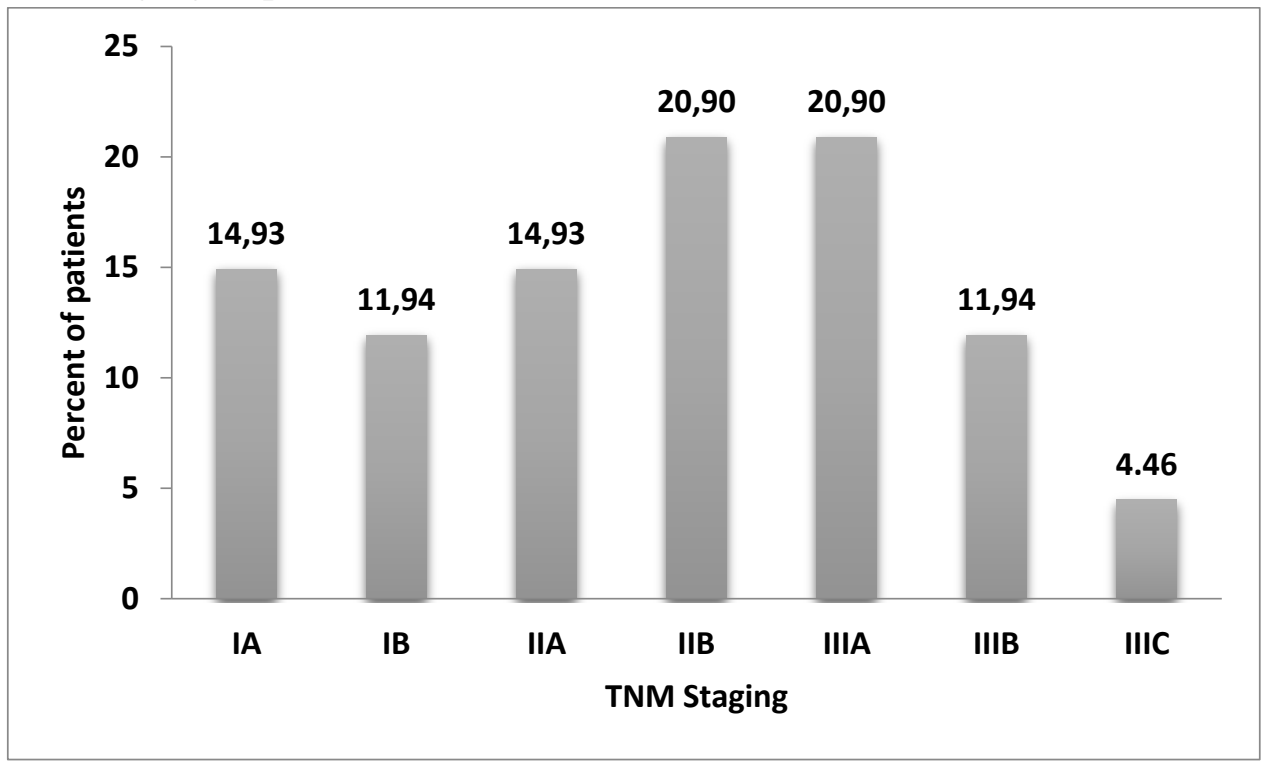

Fig. No. 4: Distribution of study subjects by follow-up analysis

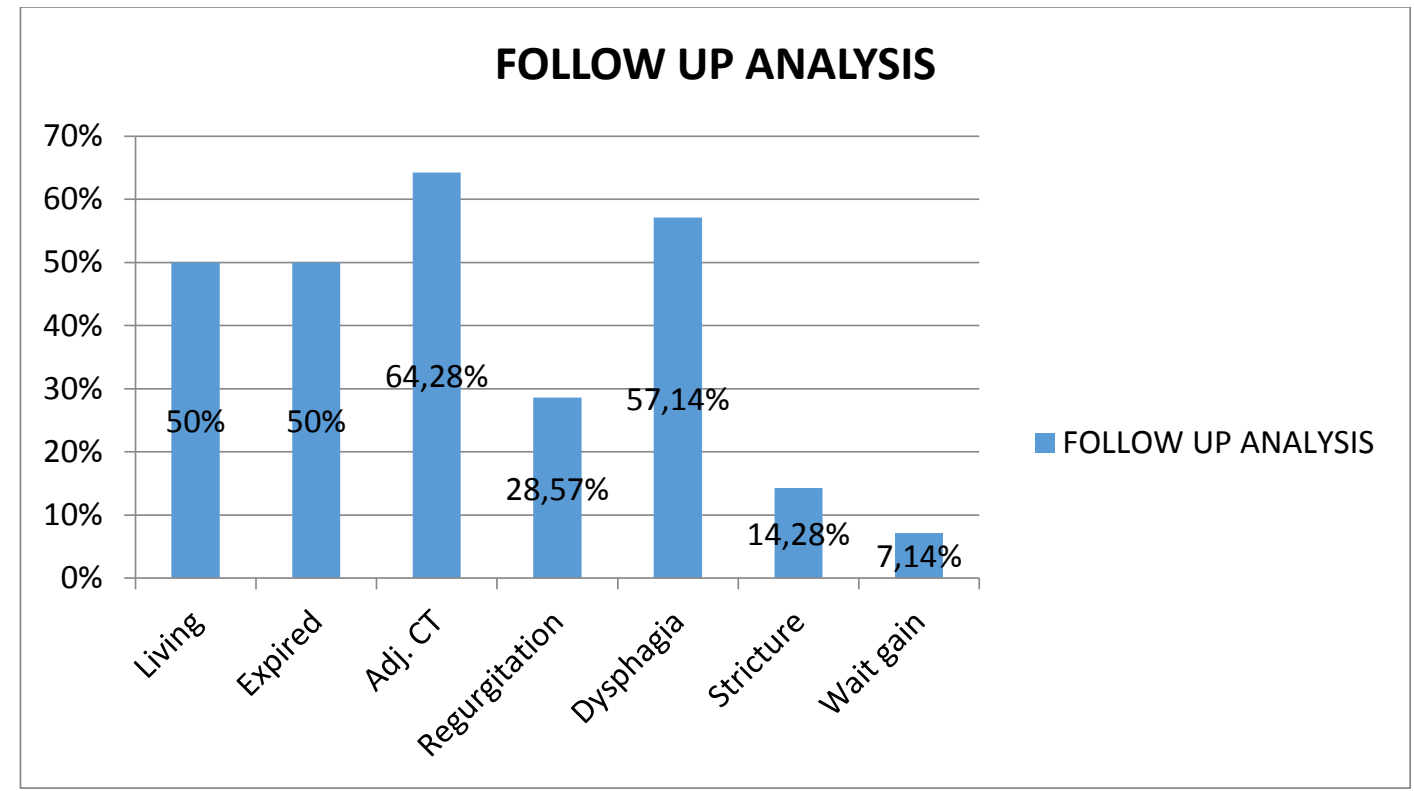


Fig. No 5: Oesophageal growth (Photo)

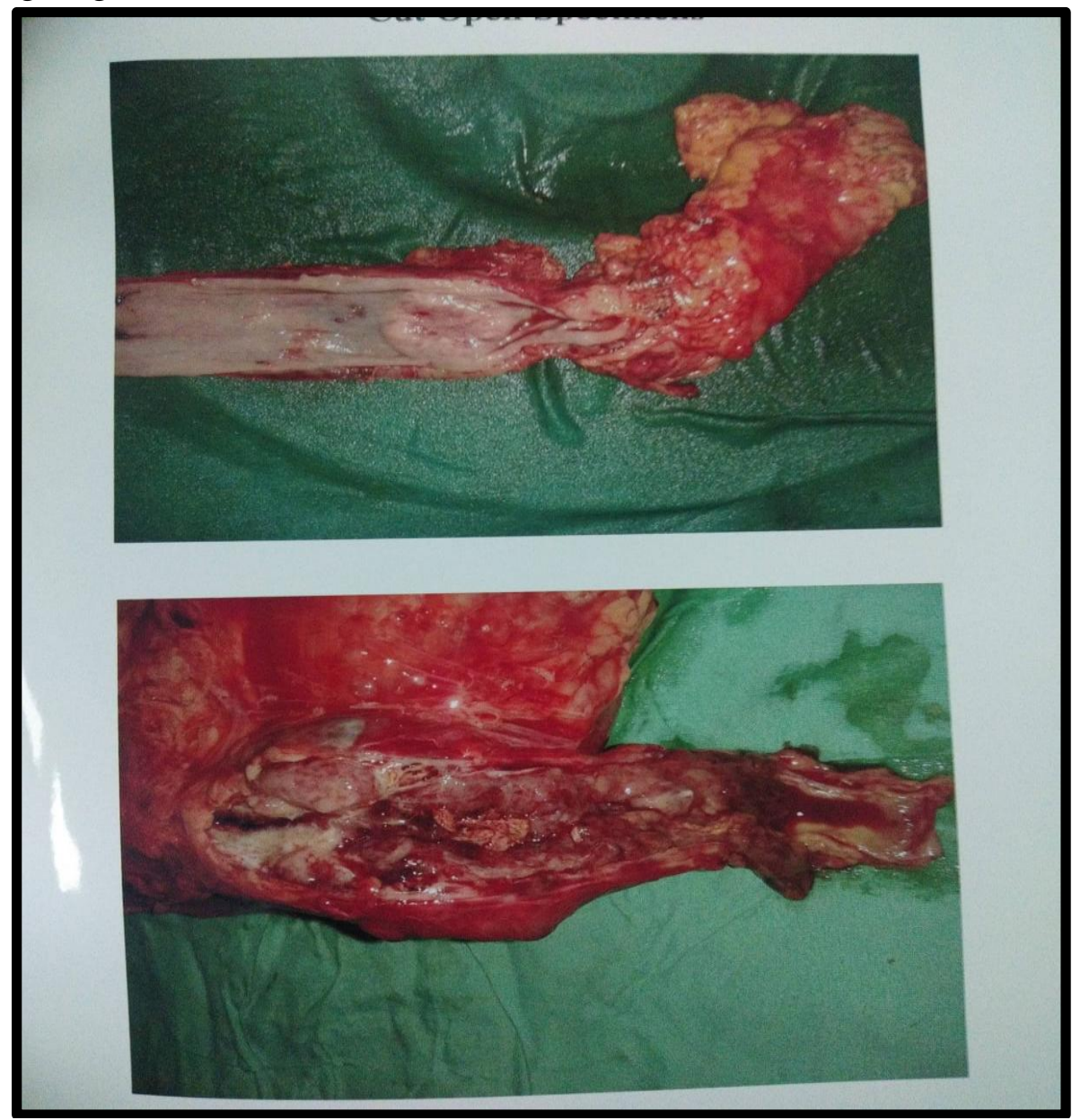

Table no. 1: Socio-demographic profile of patients $(\mathrm{N}=104)$.

\begin{tabular}{|l|c|}
\hline \multicolumn{2}{|l|}{ Parameters } \\
\hline \multicolumn{1}{|c|}{ Age } \\
\hline Age groups (Years) & Percentage (\%) \\
\hline $35-39$ & 4.80 \\
\hline $40-49$ & 21.15 \\
\hline $50-59$ & 49.06 \\
\hline $60-69$ & 20.19 \\
\hline$>70$ & 4.80 \\
\hline \multicolumn{2}{|c|}{.. Gender } \\
\hline Sex \\
\hline Male & Percentage (\%) \\
\hline Female & $19.23 \%$ \\
\hline 3. Type of Religion & 80.77 \\
\hline Religion & \\
\hline Christian & Percentage \\
\hline Hindu & $99.03 \%$ \\
\hline
\end{tabular}

Table no. 2: Surgical management given to the patients

\begin{tabular}{|l|c|c|}
\hline Treatment & Frequency & Percentage \\
\hline THE+GPU+FJ & 39 & 37.5 \\
\hline TTE+GPU+FJ & 31 & 29.81 \\
\hline Feeding Jejunostomy & 23 & 22.12 \\
\hline Feeding Gastrostomy & 2 & 1.92 \\
\hline None(patient not tolerating surg) & 9 & 8.65 \\
\hline Total & 104 & 100 \\
\hline
\end{tabular}


Table no.3: Observed complications in patients

\begin{tabular}{|l|c|c|}
\hline Complications & Frequency & Percentage \\
\hline death due to sepsis (post op) & 2 & 1.92 \\
\hline death due to pneumonia & 4 & 3.85 \\
\hline death due to cardiac arrest & 7 & 6.73 \\
\hline anastomotic stricture (post op) & 3 & 2.88 \\
\hline tension pneumothorax (post op) & 1 & 0.96 \\
\hline pleural effusion (post op) & 4 & 3.85 \\
\hline wound infection (post op) & 1 & 0.96 \\
\hline hoarseness of voice (post op) & 1 & 0.96 \\
\hline neck drain discharge (post op) & 4 & 3.85 \\
\hline ICD leak (post op) & 1 & 0.96 \\
\hline subcutaneous emphysema (post op) & 1 & 0.96 \\
\hline ectopic beats (post op) & 1 & 0.96 \\
\hline Pneumonitis (post op) & 1 & 0.96 \\
\hline
\end{tabular}

\section{Discussion}

In our study mean (SD) age of patient was 54.19 \pm 8.89 years whereas a study conducted by W. Hu et al -the mean age was 55.98yrs with SD of $9.16^{7}$ and Jian Yang Ma et. al. the mean age was found to be $55.8 \mathrm{yrs}$ with SD of $5.2^{8}$. In both studies the mean age nearly equal to our study.

In our study, out of $104(100 \%)$ patients, $84(80.77 \%)$ were males and $20(19.23 \%)$ were females which are nearly equal to a study conducted by Nozoe et. al in which 200(86.2\%) were males and $32(13.8 \%)$ were females. ${ }^{9}$ In a study conducted by Kritika Patel et al, the number of males who had oesophageal cancer was 92 $(57.9 \%)$ and females were $67(42.1 \%)^{10}$ and W. $\mathrm{Hu}$ et al, males were found to be 57(67.9\%) and female were found to be $27(32.1 \%){ }^{7}$ These findings are lesser than our present study.

99.03\% patients were found to be Christians and only $0.97 \%$ patients were found to be Hindu. This finding can be attributed to the fact that the state of Mizoram is a Christian state with majority of the population being Christians.

In our study, symptoms like history of progressive dysphagia solids to was found $91.35 \%$ patients and history of progressive dysphagia to liquids was found in $42.3 \%$ of patients. In a study done by $\mathrm{Hu} \mathrm{W}$ et al, progressive dysphagia to solids was found in $82(97.6 \%)$ patients and no one with dysphagia to liquids. ${ }^{7}$ Khan NA et al found that most common presentation was dysphagia to solids $(90 \%){ }^{11}$
In our study, $45.19 \%$ patients were affected with lower third of oesophagus, $48.08 \%$ patients were affected with middle third and $6.73 \%$ patients were affected with upper third of oesophagus on upper gastro intestinal endoscopy. Johnston et al found that SCC in the middle third of the oesophagus in $57.86 \%$ (92 cases), $31.44 \%$ (50 cases) in the lower third, and $10.8 \%$ (17 cases) in the upper third of the esophagus. ${ }^{10}$ Also in another study conducted by Zhang et al, tumour was located at upper third in $8(9.5 \%)$ patients, middle third in $62(73.8 \%)$ and lower third in $14(16.7 \%)$ patients. ${ }^{7}$ In a study by Zhu et al, tumour was located in upper third in $186(10.4 \%)$ patients, in middle third in 901 (50.6\%) patients and in lower third of oesophagus in 591(33.2\%) of patients. ${ }^{8}$

In our study Squamous cell carcinoma was found in $99.03 \%$ (103) of patients and adenocarcinoma was found in only $0.97 \%$ patients on Upper GI endoscopy. Kritika Patel et al found that Squamous-cell carcinoma (SCC) accounted for $92.45 \%$ (147cases), while adenocarcinomas (ADC) accounted for $7.54 \%$ (12 cases) from the total of 159 cases. ${ }^{10}$ In Ma JY et al study, SCC was detected in $1610(90.3 \%)$ of patients, adenocarcinoma was detected in $97(5.4 \%)$ of patients and other carcinoma was detected in 75 $(4.2 \%)$ of patients. ${ }^{8}$ In a study by Khan NA et al, 629 patients had SSC (92.5\%) while 50 (7.35\%) patients had adenocarcinoma. ${ }^{11}$ These results were comparable to previous results.

In our study, $37.14 \%$ patients had ulcerative growth, $45.72 \%$ patients had proliferative growth 
and $17.14 \%$ patients had ulceroproliferative growth on gross macroscopic examination of resected specimen. Kuwanoetal found superficial and protruding growth in $9.4 \%$ patients, superficial and flat growth in $26.8 \%$ patients,superficial and distinct growth in 3.9\% patients, protruding growth in $10.2 \%$ patients, ulcerative and localized growth in $12.6 \%$ patients, ulcerative and infiltrating growth in $34.6 \%$ patients, diffuse and infiltrating growth in $1.6 \%$ patients and miscellaneous nature of growth in $0.8 \%$ patients. $^{12}$ Khan NA et al found that morphologically the lesion was ulcerative, infiltrative and polypoid in $24.5 \%, 20.14 \%$ and $16.17 \%$ respectively. ${ }^{11}$

In our study, $14.93 \%$ patients were detected with IA stage, $11.94 \%$ patients were detected with stage IB, $14.93 \%$ patients were detected with stage IIA, $20.90 \%$ patients were detected with stage IIB and $20.90 \%$ patients were detected with stage IIIA. Only $11.94 \%$ patients were detected with stage IIIB and $4.46 \%$ were detected with stage IIIC. In a study done by Su D et al, $20.6 \%$ patients were detected with IIIA stage, $23.1 \%$ patients were detected with IIB stage, 3.8\% patients were detected with IA and $15.6 \%$ were detected with IIA stages.11.3\% patients were detected with IIIB stage and $13.1 \%$ patients were detected with IB stage. ${ }^{13}$

Of the 25 patients operated for oesophageal resection in our study in the prospective study period, only $14(56 \%)$ patients came for follow up. Of the patients came for follow up, 7 (50\%) expired during follow up. Total of $9(64.28 \%)$ patients from the followed up patients received adjuvant chemotherapy. None of the patients received adjuvant radiotherapy. 4 (28.57\%) patients complained of regurgitation on follow up. $8(57.14 \%)$ patients complained dysphagia to solids on follow up. None complained dysphagia to liquids. 2 (14.28\%) of patients showed evidence of stricture on upper GI endoscopy on follow up. 1 patient $(7.14 \%)$ was found to have gained weight and eating well after removal of feeding jejunostomy.

\section{Conclusion}

Results of present study suggest that squamous cell carcinoma is the major histologic type found in esophageal cancer patients. Most of patients presented in advance stage and had grave prognosis. Tumour was found to be moderately differentiated with IIB and IIIA stage. Most of the follow up patients received adjuvant chemotherapy and majority didn't showed weight gain after removal of feeding jejunostomy.

\section{References}

1. Law S. Cancer of oesophagus. 12th ed. Zinner M, Ashley S:Maingot s abdominal operations; 2013.

2. Sinha R, Anderson DE, McDonald SS, Greenwald P. Cancer risk and diet in India. J Postgrad Med. 2003 Jul-Sept ;49(3):2228.

3. Alderson D. The Oesophagus. 26th ed. Williams NS, Bulstrode CJK, O'Connell PR: Bailey and Love's Short Practice of Surgery;2013.

4. Rai G. Clinicopathological study of cancer oesophagus. Mangalore: Rajiv Gandhi University of Health Sciences, Karnataka. 2012.

5. National Cancer Registry Programme. Two year report of the Population Based Cancer Registries Under North Eastern Regional Cancer Registry 2005-2006. Bangalore:Indian Council Of Medical Research; 2007.

6. Civil Hospital, Aizawl Medical Records.

7. W Hu, Y Liang, S Zhang, Y Hu, J Liu. Ten-year survival of patients with oesophageal squamous cell carcinoma. S Afr J Surg 2013;51(2):62-66.

8. Jian-Yang Ma, Zhu Wu, Yun Wang, Yong-Fan Zhao, Lun-Xu Liu, Ying-Li Kou, Qing-Hua Zhou. Clinicopathologic characteristics of esophagectomy foresophageal carcinoma in elderly patients. World J Gastroenterol 2006 February 28; 12(8):1296-1299 
9. Nozoe T, Saeki H, Ohga T, Sugimachi K. Clinicopathological characteristics of oesophageal squamous cell carcinoma in young patients. Ann Thorac Surg. 2001;72:1914-17.

10. Kirtika Patel, Johnston Wakhisi, Simeon Mining, Ann Mwangi and Radheka Patel. Esophageal Cancer, the Topmost Cancer at MTRH in the Rift Valley, Kenya, and Its Potential Risk Factors. Hindawi Publishing Corporation ISRN Oncology;2013:2-3

11. Khan NA, Maqbool LM, Afroz F, Kharadi MY. Clinicopathological profile of carcinoma oesophagus and oesophagogastric junction in Kashmir. JKPractitioner. 2004;11(3):182-185.

12. Kuwano H, Nakajima M, Miyazaki T, Kato H. Distinctive clinicopathological characteristics in oesophageal squamous cell carcinoma. Ann Thorac Cardiovasc Surg. 2003 Feb;9(1):6-13.

13. Su D, Zhou X, Chen Q, Jiang Y, Yang X, Zheng W, Tao K, Wu J, Yan Z, Liu L, Wu $\mathrm{S}$, Mao W. Prognostic nomogram for thoracic esophageal squamous cell carcinoma after radical esophagectomy. PLoS One. 2015 Apr 20;10(4):e0124437. 